\title{
ENRAIZAMENTO DE ESTACAS APICAIS DE FIGUEIRA 'ROXO DE VALINHOS' EM FUNÇÃO DE ÉPOCA DE COLETA EAIB
}

\author{
Rooting of apical cuttings of 'Roxo de Valinhos' fig tree as a function of the collection time and IBA
}

\author{
Tatiane Ohland ${ }^{1}$, Rafael Pio ${ }^{2}$, Edvan Alves Chagas ${ }^{3}$, Wilson Barbosa ${ }^{4}$, Tailene Elisa Kotz ${ }^{1}$, Simone Daneluz ${ }^{1}$
}

\begin{abstract}
RESUMO
Estacas apicais de figueira 'Roxo de Valinhos' coletadas em épocas distintas, podem apresentar enraizamento diferenciado, o que propiciará, na prática, saber em qual época devem-se aproveitar as estacas para a produção de mudas. Objetivou-se, no presente trabalho, avaliar a época de coleta e o tratamento com AIB, no enraizamento de estacas apicais da figueira 'Roxo de Valinhos'. Estacas caulinares lenhosas da porção apical dos ramos, coletadas no final da primeira quinzena dos meses de maio, junho, julho, agosto e setembro, foram padronizadas com $20 \mathrm{~cm}$ de comprimento e diâmetro próximo a $7 \mathrm{~mm}$ e tratadas ou não com AIB à $2000 \mathrm{mg} \mathrm{L}{ }^{-1}$, por $10 \mathrm{seg}$. Em seguida, as estacas foram enterradas em leito de areia umedecido, sob telado constituído de sombrite com 50\% de luminosidade. Decorridos 60 dias, foi mensurada a porcentagem de estacas vivas, enraizadas, brotadas, número médio de brotações e raízes por estaca. Concluiu-se que as estacas apicais de figueira 'Roxo de Valinhos' devem ser coletadas em junho e, posteriormente, tratadas com $2000 \mathrm{mg} \mathrm{L}^{-1}$ de AIB.
\end{abstract}

Termos para indexação: Ficus carica L., ácido indolbutírico, propagação.

\section{ABSTRACT}

Apical cuttings of 'Roxo de Valinhos' fig tree collected at different times, may present differentiated rooting, which could propitiate, in practice, the knowledge of the right moment to use the cuttings for their propagation. The aim of the present work was to verify the effect of the collection time of the cutting and the treatment with IBA on the rooting of the apical cuttings of 'Roxo de Valinhos' fig tree. Woody cuttings of apical portion of the branches were collected at the end of the first fortnight of the months May, June, July, August, and September. They were standardized at $20 \mathrm{~cm}$ length and $7 \mathrm{~mm}$ diameter. The cutting was treated or not with $2000 \mathrm{mg} \mathrm{L}^{-1}$ IBA for 10 seconds. Soon after, the cuttings were buried in a moist sand bed at nursery conditions with $50 \%$ light. After 60 days, the percentage of live cuttings and their rooting, shooting, average number of shoots and roots were evaluated. It was concluded that the apical cuttings of 'Roxo de Valinhos' fig tree should be collected in June and treated with $2000 \mathrm{mg} \mathrm{L}^{-1}$ IBA.

Index terms: Ficus carica L., indolbutyric acid, propagation.

\section{(Recebido em 27 de março de 2008 e aprovado em 27 de agosto de 2008)}

\section{INTRODUÇÃO}

A propagação da figueira (Ficus carica L.) é realizada por meio de estacas caulinares lenhosas, aproveitando-se o material oriundo da poda hibernal, efetuada entre os meses de junho e julho (ALVARENGA et al., 2007). Em vista da grande importância dessa cultura, observa-se que existem várias técnicas de manejo que precisam ser melhoradas, como, por exemplo, o plantio das estacas diretamente na cova, onde são utilizadas estacas com dimensões de, aproximadamente, $40 \mathrm{~cm}$ de comprimento e diâmetro de $3 \mathrm{~cm}$. Essa prática vem acarretando elevado custo de implantação do pomar, devido ao baixo índice de enraizamento das estacas, por não haver coincidência da estaquia com o período chuvoso, principalmente nas regiões Sul e Sudeste, originando desuniformidade na formação do figueiral e, muitas vezes, necessidade de replantio (CHALFUN \& HOFFMANN, 1997; GONÇALVES et al., 2003).

A solução para a propagação da figueira seria o enraizamento prévio das estacas em ambiente protegido, propiciando a seleção de plantas de qualidade e plantio no período chuvoso, possibilitando a obtenção de um pomar uniforme e vigoroso. Nesse caso, a utilização de estacas de menores dimensões facilita o manejo das mudas,

\footnotetext{
${ }^{1}$ Graduandas de Agronomia - Universidade Estadual do Oeste do Paraná/UNIOESTE - Rua Pernambuco, no 1777, Centro - Cx. P. 1008 - 85960-000 Marechal Cândido Rondon,PR - tatianeohland@hotmail.com taileneelisa@hotmail.com simonedaneluz@yahoo.com.br

${ }^{2}$ Engenheiro Agrônomo, Doutor, Professor Adjunto da Universidade Estadual do Oeste do Paraná/UNIOESTE - Rua Pernambuco, no 1777 , Centro Cx. P. 1008 - 85960-000 - Marechal Cândido Rondon,PR - rafaelpio@hotmail.com - Bolsista Produtividade em Pesquisa CNPq.

${ }^{3}$ Engenheiro Agrônomo, Doutor, Pesquisador Científico do Centro Avançado de Pesquisa Tecnológica do Agronegócio de Frutas - Instituto Agronômico/ IAC - Avenida Luiz Pereira dos Santos, 1500, Corrupira, 13214-820 - Jundiaí, SP - echagas@iac.sp.gov.br - Bolsista Produtividade em Pesquisa CNPq ${ }^{4}$ Biólogo, Mestre - Centro Experimental Central, Instituto Agronômico/IAC - Cx. P. 28 - 13001-970 -Campinas, SP - wbarbosa@iac.sp.gov.br - Bolsista Produtividade em Pesquisa CNPq.
} 
frente à utilização de recipientes de menor dimensão e, conseqüentemente, aumentando a densidade de mudas no viveiro. Estacas oriundas da porção apical vêm demonstrando serem promissoras na propagação da figueira, em função aos bons resultados obtidos com o enraizamento dessa porção do ramo (PIO et al., 2004). Entretanto, no enraizamento das estacas apicais coletadas em agosto, sob telado constituído de sombrite com $50 \%$ de luminosidade, houve aproximadamente $50 \%$ de enraizamento, sem a utilização de ácido indolbutírico (AIB) (PIO et al., 2006b).

A época do ano está estreitamente relacionada com a consistência da estaca; estacas coletadas no período de crescimento vegetativo intenso (primavera/verão) apresentam-se mais herbáceas e, de modo geral, mostram maior capacidade de enraizamento quando coletadas nessa época, enquanto estacas coletadas no inverno possuem maior grau de lignificação e tendem a enraizar menos (FACHINELLO et al., 2005).

No caso de estacas lenhosas de frutíferas de clima temperado, reservas mais abundantes de carboidratos correlacionam-se com maiores porcentagens de enraizamento e sobrevivência de estacas. Assim, a real importância dos carboidratos para formação de raízes é que a auxina requer fonte de carbono para a biossíntese de ácidos nucléicos e proteínas, levando à necessidade de energia e carbono para formação das raízes (HARTMANN et al., 2002).

No manejo da figueira em regiões de inverno ameno, o manejo da poda das plantas durante o período hibernal, realizadas em épocas distintas, possibilita o maior escalonamento da produção, adotando-se simultaneamente podas precoces, visando a antecipação da produção e podas tardias, aumentando o período de colheita (NORBERTO et al., 2001a).

Estacas apicais de figueira 'Roxo de Valinhos', coletadas em épocas distintas, possivelmente apresentarão potenciais rizogênicos distintos, o que propiciará, na prática, saber em qual época devem-se aproveitar os propágulos para a produção de mudas. Além disso, com a introdução de um novo sistema de condução da figueira por meio de desponte na obtenção de figos verdes, ocorre a formação de até 96 ponteiros, quando adotados quatro despontes ao longo da condução da figueira, em seu ciclo produtivo. Torna-se importante estudar a possibilidade de enraizamento das estacas apicais em épocas de podas distintas, o que decorre em vantagem no maior aproveitamento dos propágulos a serem multiplicados (ALVARENGA et al., 2007; CHALFUN \& HOFFMANN, 1997).
Objetivou-se, no presente trabalho, verificar o potencial rizogênico de estacas apicais lenhosas de figueira 'Roxo de Valinhos', coletadas em diferentes épocas, associada ao tratamento com ácido indolbutírico (AIB).

\section{MATERIAL E MÉTODOS}

Estacas caulinares lenhosas, da porção apical dos ramos da figueira 'Roxo de Valinhos' foram coletadas no final da primeira quinzena dos meses de maio, junho, julho, agosto e setembro, em um pomar comercial situado no município de Quatro Pontes-PR. Em cada época de coleta, as estacas foram transportadas após a coleta ao Setor de Fruticultura, da Universidade Estadual do Oeste do Paraná (UNIOESTE), Marechal Cândido Rondon-PR, para a execução do experimento.

As estacas foram padronizadas com $20 \mathrm{~cm}$ de comprimento, diâmetro próximo a $7 \mathrm{~mm}$, sendo efetuado um corte em bisel na base da estaca e outro reto no ápice, e após tratadas ou não em solução de AIB a $2000 \mathrm{mg} \mathrm{L}^{-1}$, por $10 \mathrm{seg}$. Em seguida, as estacas foram enterradas a $2 /$ 3 de seu comprimento em leito de areia umedecido, sob telado constituído de sombrite $50 \%$. O delineamento experimental adotado foi o inteiramente casualizado, em esquema fatorial 5 x 2, com quatro repetições e 10 estacas por unidade experimental, perfazendo um montante de 480 estacas. Decorridos 60 dias de cada época de coleta das estacas, foram mensurados os seguintes dados biométricos: porcentagem de estacas vivas, enraizadas, brotadas, número médio de brotações e raízes por estaca.

Os dados foram submetidos à análise de variância e as médias comparadas pelo teste Tukey, ao nível de 5\% de probabilidade (GOMES, 2000). As análises foram realizadas pelo programa computacional Sistema para Análise de Variância - SISVAR (FERREIRA, 2000).

\section{RESULTADOS E DISCUSSÃO}

Não houve interação significativa entre a época de coleta das estacas e o tratamento com AIB para a variável porcentagem de estacas vivas; no entanto, estacas coletadas entre os meses de junho a agosto, apresentaram maior sobrevivência, independente do tratamento com AIB (Tabela 1). Resultados semelhantes foram observados para a porcentagem de estacas brotadas e o número médio de brotos, porém, com maior porcentagem de brotação nos meses de junho (55\%) e agosto (70\%) (Tabela 1).

Estacas coletadas nas podas realizadas em plantas de figueira 'Roxo de Valinhos', situadas no Oeste do Paraná, apresentaram maior porcentagem de brotação em junho e agosto, possivelmente por estarem associadas à 
entrada e à saída do período de dormência, respectivamente e, conseqüentemente, por apresentarem fluxo e mobilização das substâncias de reservas (carboidratos), responsáveis pela emissão das brotações nas estacas.

A baixa brotação dos propágulos vegetativos pode estar correlacionada a fatores intrínsecos ao material vegetal, como a concentração de fitormônios e de carboidratos nos ramos (HARTMANN et al., 2002). No caso de estacas apicais de figueira, devido à translocação das substâncias de reservas (carboidratos) para o sistema radicular durante a dormência, a coleta das estacas, durante o repouso vegetativo, não favorece a produção de mudas.

Tabela 1 - Porcentagem de estacas vivas, brotadas e número médio de brotos de estacas apicais de figueira 'Roxo de Valinhos', coletadas em diferentes épocas. Marechal Cândido Rondon-PR, UNIOESTE, 2008.

\begin{tabular}{lccc}
\hline $\begin{array}{c}\text { Época de } \\
\text { coleta das } \\
\text { estacas }\end{array}$ & $\begin{array}{c}\text { Estacas } \\
\text { vivas }(\%)\end{array}$ & $\begin{array}{c}\text { Estacas } \\
\text { brotadas } \\
(\%)\end{array}$ & $\begin{array}{c}\text { Número } \\
\text { médio de } \\
\text { brotos }\end{array}$ \\
\hline Maio & $58,5 \mathrm{~b}$ & $2,5 \mathrm{~b}$ & $0,50 \mathrm{~b}$ \\
Junho & $100,0 \mathrm{a}$ & $55,0 \mathrm{a}$ & $2,24 \mathrm{a}$ \\
Julho & $90,0 \mathrm{a}$ & $12,5 \mathrm{~b}$ & $0,96 \mathrm{ab}$ \\
Agosto & $87,5 \mathrm{a}$ & $70,0 \mathrm{a}$ & $1,75 \mathrm{ab}$ \\
Setembro & $70,0 \mathrm{~b}$ & $7,5 \mathrm{~b}$ & $1,57 \mathrm{ab}$ \\
\hline C.V. $(\%)$ & 13,16 & 19,18 & 15,47 \\
\hline
\end{tabular}

* Médias seguidas pela mesma letra, maiúsculos e minúsculos na coluna, não diferem entre si pelo teste Tukey, a $5 \%$ de probabilidade.

Para a porcentagem de estacas enraizadas, houve maior enraizamento para as estacas coletadas no mês de agosto sem o tratamento com AIB (42,5\%); quando se submeteu as estacas coletadas nas diferentes épocas, ao tratamento basal com $2000 \mathrm{mg} \mathrm{L}^{-1}$ de AIB, houve aumento expressivo para as estacas coletadas em junho (incremento de $70 \%$ de enraizamento), não ocorrendo diferença entre a ausência e o tratamento com AIB nas demais épocas de coleta (Tabela 2).

Resultados semelhantes foram observados para estacas lenhosas coletadas na porção mediana dos ramos, ocorrendo diferença entre o não tratamento com AIB e o tratamento com $100 \mathrm{mg} \mathrm{L}^{-1}$, na primeira quinzena de junho (incremento de $35 \%$ de enraizamento); no entanto, a partir da segunda quinzena de junho ao final de agosto, não houve aumento significativo da porcentagem de enraizamento entre estacas tratadas e não tratadas com AIB (NORBERTO et al., 2001b).
O teor de auxinas em tecidos com maior grau de diferenciação é muito baixo em espécies perenes de clima temperado, onde o menor teor de auxinas, em julho, pode ser apontado como um dos fatores que mais contribuem para que, nessa época, se obtenha o menor enraizamento das estacas (HINOJOSA, 2000), associado ainda à menor quantidade de carboidratos nas estacas.

A importância dos carboidratos para formação de raízes é que a auxina requer fonte de carbono para a biossíntese de ácidos nucléicos e proteínas, levando à necessidade de energia e carbono para formação das raízes (HARTMANN et al., 2002). Por isso, é importante coletarse as estacas apicais de figueira no momento da entrada ou saída do período de dormência, em razão da presença de fotoassimilados nos ramos.

Para o número médio de raízes, não houve diferença entre as estacas coletadas entre os meses de maio a setembro, com o não tratamento com AIB, a exceção de estacas coletadas em julho, que não enraizaram; quando se submeteu as estacas à concentração de $2000 \mathrm{mg} \mathrm{L}^{-1}$, houve incremento de 70,56 raízes para as estacas coletadas em junho, 42,25 raízes para as estacas coletadas em agosto e 29,78 para as coletadas em setembro, sendo que, em junho, ocorreu a maior emissão de raízes (Tabela 2).

Segundo Fachinello et al. (2005), entre as principais funções biológicas das auxinas, podem-se citar o crescimento de órgãos, especialmente as raízes. No presente trabalho, detectou-se ainda que as estacas enraizadas nos tratamentos sem AIB, ao longo de todas as épocas de estaquia, apresentaram um sistema radicular reduzido, o que pode trazer problemas no desenvolvimento das mudas quando transplantadas.

Quanto às estacas coletadas da porção apical dos ramos, Pio et al. (2006a) referem-se ao alto potencial rizogênico dos fragmentos coletados nessa posição dos ramos, principalmente no que tange ao número de raízes por estaca, onde os mesmos autores obtiveram 32 raízes, em média, em estacas tratadas com AIB (2000 $\left.\mathrm{mg} \mathrm{L}^{-1}\right)$ e coletadas em agosto. No entanto, para as estacas apicais coletadas em junho e tratadas com a mesma concentração de AIB, houve aumento aproximadamente de 41 raízes por estaca (Tabela 2), em média, em comparação à citação mencionada.

A influência da época de estaquia no enraizamento de estacas ocorre por causa das variações no conteúdo dos cofatores na formação e no acúmulo de inibidores do enraizamento, o que provavelmente explique a resposta mais ou menos efetiva à aplicação do regulador, ao longo das épocas testadas (DUTRA \& KERSTEN, 1996). 
Tabela 2 - Porcentagem de estacas enraizadas e número médio de raízes de estacas apicais de figueira 'Roxo de Valinhos', coletadas em diferentes épocas e submetidas ou não ao tratamento com AIB (2000 mg L $\left.{ }^{-1}\right)$. Marechal Cândido Rondon-PR, UNIOESTE, 2008.

\begin{tabular}{lcccc}
\hline \multirow{2}{*}{$\begin{array}{c}\text { Época de coleta das } \\
\text { estacas }\end{array}$} & \multicolumn{2}{c}{ Estacas enraizadas $(\%)$} & \multicolumn{2}{c}{ Número médio de raízes } \\
\cline { 2 - 5 } & Sem AIB & Com AIB & Sem AIB & Com AIB \\
\hline Maio & $5,0 \mathrm{Ab}$ & $7,5 \mathrm{Ac}$ & $3,25 \mathrm{Aa}$ & $5,25 \mathrm{Ad}$ \\
Junho & $5,0 \mathrm{Bb}$ & $75,0 \mathrm{Aa}$ & $2,25 \mathrm{Ba}$ & $72,81 \mathrm{Aa}$ \\
Julho & $0 \mathrm{Ab}$ & $12,5 \mathrm{Ac}$ & $0 \mathrm{Ab}$ & $7,58 \mathrm{Ad}$ \\
Agosto & $42,5 \mathrm{Aa}$ & $47,5 \mathrm{Ab}$ & $3,91 \mathrm{Ba}$ & $46,16 \mathrm{Ab}$ \\
Setembro & $2,5 \mathrm{Ab}$ & $13,5 \mathrm{Ac}$ & $0,50 \mathrm{Bb}$ & $30,28 \mathrm{Ac}$ \\
\hline \multicolumn{1}{c}{ C.V.(\%) } & \multicolumn{3}{c}{16,07} \\
\hline
\end{tabular}

* Médias seguidas pela mesma letra, maiúsculas e minúsculas na coluna, não diferem entre si pelo teste Tukey, a 5\% de probabilidade.

\section{CONCLUSÃO}

As estacas apicais de figueira 'Roxo de Valinhos' devem ser coletadas em junho e, posteriormente, tratadas com $2000 \mathrm{mg} \mathrm{L}^{-1}$ de AIB.

\section{REFERÊNCIAS BIBLIOGRÁFICAS}

ALVARENGA, A. A.; ABRAHÃO, E.; FRÁGUAS, J. C.; CARVALHO, V. L.; SILVA, R. A.; SANTA CECILIA, L. V. C.; CUNHA, R. L.; SILVA, V. J. Figo (Ficus carica L.). In: TRAZILBO JÚNIOR, J. P.; MADELAINE, V. (Orgs.). 101 culturas: manual de tecnologias agrícolas. Belo Horizonte: Epamig, 2007. p. 365-372.

CHALFUN, N. N. J.; HOFFMANN, A. Propagação da figueira. Informe Agropecuário, Belo Horizonte, v. 18, n. 188, p. 9-13, 1997.

DUTRA, L. F.; KERSTEN, E. Efeito do substrato e da época de coleta dos ramos no enraizamento de estacas de ameixeira (Prumus salicina L.). Ciência Rural, Santa Maria, v. 26, n. 3, p. 361-366, set./dez. 1996.

FACHINELLO, J. C.; HOFFMANN, A.; NACHTIGAL, J. C. Propagação de plantas frutíferas. Brasília, DF: Embrapa, 2005. $221 \mathrm{p}$.

FERREIRA, D. F. Análise estatística por meio do SISVAR (Sistema para Análise de Variância) para Windows versão 4.0. In: REUNIÃO ANUAL DA REGIÃO BRASILEIRA DA SOCIEDADE INTERNACIONAL DE BIOMETRIA, 45., 2000, São Carlos. Anais... São Carlos: UFSCar, 2000. p. 255-258.
GOMES, F. P. Curso de estatística experimental. 14. ed. Piracicaba: USP/ESALQ, 2000. 477 p.

GONÇALVES, F. C.; CHALFUN, N. N. J.; ALVARENGA, A. A.; MIRANDA, C. S. Influência da forma de acondicionamento sob frio na sobrevivência de mudas de figueira. Ciência e Agrotecnologia, Lavras, v. 27, n. 4, p. 798-803, 2003.

HARTMANN, H. T.; KESTER, D. E.; DAVIES JUNIOR, F. T.; GENEVE, R. L. Plant propagation: principles and practices. 7. ed. New Jersey: Prentice Hall, 2002. 880 p.

HINOJOSA, G. F. Auxinas. In: CID, L. P. B. Introdução aos hormônios vegetais. Brasília, DF: Embrapa-SPI, 2000. p. 15-54.

NORBERTO, P. M.; CHALFUN, N. N. J.; PASQUAL, M.; VEIGA, R. D.; MOTA, J. H. Efeito da época de poda, cianamida hidrogenada e irrigação na antecipação de figos verdes. Pesquisa Agropecuária Brasileira, Brasília, v. 36, n. 11, p. 1363-1369, 2001a.

NORBERTO, P. M.; CHALFUN, N. N. J.; PASQUAL, M.; VEIGA, R. D.; PEREIRA, G. E.; MOTA, J. H. Efeito da época de estaquia e do AIB no enraizamento de estacas de figueira (Ficus carica L.). Ciência e Agrotecnologia, Lavras, v. 25, n. 3, p. 533-541, 2001b.

PIO, R.; RAMOS, J. D.; CHALFUN, N. N. J.; COELHO, J. H. C.; GONTIJO, T. C. A.; CARRIJO, E. P.; VILLA, F. Enraizamento adventícios de estacas apicais de figueira e desenvolvimento inicial das plantas no campo. Ciência e Agrotecnologia, Lavras, v. 28, n. 1, p. 215-221, 2004. 
PIO, R.; CHAGAS, E. A.; BARBOSA, W.; MENDONÇA, $\quad$ PIO, R.; RAMOS, J. D.; CHALFUN, N. N. J.; GONTIJO, T. V.; SCARPARE FILHO, J. A.; GUIMARAES, V. F. $\quad$ C. A.; MENDONÇA, V.; CARRIJO, E. P.; CHAGAS, E. A. Enraizamento de estacas de figueira coletadas em diferentes Propagação de estacas apicais de figueira: diferentes posições no ramo e ambientes de propagação distintos. Scientia Agrária Paranaensis, v. 5, p. 1-5, 2006 a. ambientes, ácido indolbutírico e tipo de estaca. Ciência e Agrotecnologia, Lavras, v. 30, n. 5, p. 1021-1026, 2006 b. 